\title{
Inhibitory action of a new lectin from Xerocomus chrysenteron on cell-substrate adhesion
}

\author{
Claire Marty-Detraves, ${ }^{1 *}$ Frédéric Francis, ${ }^{2 *}$ Laurent Baricault, ${ }^{3}$ \\ Didier Fournier ${ }^{1}$ and Laurent Paquereau ${ }^{1}$ \\ ${ }^{1}$ IPBS UMR5089, Biophysique et Biotechnologie des Protéines, Toulouse, France; ${ }^{2}$ Unité de Zoologie générale et \\ appliquée, Faculté universitaire des Sciences agronomiques, Gembloux, Belgique; ${ }^{3}$ Laboratoire de Biologie Cellulaire et \\ Moléculaire du Contrôle de la Prolifération, Université Paul Sabatier, Toulouse, France
}

Received 13 January 2003; accepted 12 June 2003

\begin{abstract}
Lectins are carbohydrate-binding proteins which potentially link to cell surface glycoconjugates and affect cell proliferation. We investigated the effect of a new lectin from the mushroom Xerocomus chrysenteron (XCL) on cell proliferation using adherent and suspension cell lines. XCL caused a dose-dependent inhibition of proliferation of the adherent cell lines NIH-3T3 and HeLa. Several experiments suggest that disruption of cell-substrate adhesion is the main factor affecting cell growth inhibition. (i) No antiproliferative effect was observed on the SF9 cell line, which does not require to be attached to grow. (ii) XCL was shown to affect the adherence of cells following their suspension by trypsin treatment. (iii) XCL was localized on the cell surface where it would act as a coating agent. (iv) XCL induced morphological changes from well spread to rounded cells and disrupted the actin cytoskeleton. By contrast, flow cytometric analysis showed that XCL does not interfere with the cell cycle, and does not induce apoptosis. (Mol Cell Biochem 258: 49-55, 2004)
\end{abstract}

Key words: lectin, proliferation, adherence

\section{Introduction}

The carbohydrate binding proteins play a key role in the control of normal and pathological processes in various living organisms, participating in many cell reactions such as cell growth and division [1]. Since lectins distinguish themselves from all other proteins by their specific carbohydrate binding activity, one can reasonably assume that their physiological role involves their sugar binding activity [2]. Indeed, some lectins inhibit cell proliferation by cross-linking cell-surface glycoconjugates without any need for internalization [3]. The lectin from the common edible mushroom Agaricus bisporus $(\mathrm{ABL})$ has been shown to have a reversible antiproliferative

*The contribution of C.M-D and F.F. Should be considered equivalent effect without inducing any cytotoxicity in a wide range of epithelial cell types [4]. The lectin from the mushroom Xerocomus chrysenteron (XCL) belongs to the same group of lectins firstly described for ABL and AOL (Arthrobotris oligospora lectin) for sequence homology and sugar specificity [5]: XCL and ABL, sharing 55\% sequence identity, are both specific for $\mathrm{N}$-acetyl galactosamine and galactose. Consequently, the antiproliferative activity of XCL was studied using different cell lines in order to assess the mechanism by which this lectin could potentially elicit its biological effects.

The effect of XCL on cell growth was determined using two adherent mammalian cell lines (HeLa and NIH-3T3) and a non-adherent insect cell line (SF9). To investigate the mode of action of the fungal lectin, the anti-adhesion properties were studied in relation to the implication of XCL as a cell surface coating agent. The strong binding properties of XCL 
on the cell surface were visualized by immunofluorescence microscopy, suggesting that it could inhibit cell anchorage leading to cell antiproliferation. Moreover, the effect of XCL on the actin cytoskeleton of cells was also investigated.

\section{Materials and methods}

\section{Materials}

A clone encoding a lectin from Xerocomus chrysenteron was obtained by PCR from primers deduced from peptidic sequences [6]. This clone was expressed in E. coli with a histidine tail at the N-terminus. Purification of the protein (XCL) was achieved by affinity chromatography using nickel as ligand. Purified extracts were found to be devoid of any contaminant as assessed by overloaded SDS-PAGE.

Cell proliferation reagent WST-1 was purchased from Roche for the colorimetric assays to quantify cell viability by mitochondrial activity assays. Trypsin/EDTA $0.05 \% / 0.02 \%$ (w/v) in PBS was purchased from Biochrom AG.

\section{Primary antibodies}

Polyclonal antibodies directed against native XCL protein were obtained by incubation of rabbit erythrocytes with the lectin, followed by intravenous injection into the animal. These antibodies recognized only the native form and not the denatured form. Mouse anti-actin monoclonal antibodies (MAB1501) were purchased from Chemicon International. Secondary antibodies FITC-labelled goat anti-rabbit and goat anti-mouse antibodies were purchased from Molecular Probes.

\section{Cell culture}

SF9 cells were grown in SF900 medium at $28^{\circ} \mathrm{C}$ in $25 \mathrm{~cm}^{2}$ flasks. HeLa and NIH-3T3 cells were grown in Dulbecco's modified Eagle's medium (DMEM) supplemented with $10 \%$ fetal calf serum, $100 \mathrm{U} \cdot \mathrm{ml}^{-1}$ penicillin, $100 \mu \mathrm{g} \cdot \mathrm{ml}^{-1}$ streptomycin, and $2 \mathrm{mM}$ glutamine in a $5 \% \mathrm{CO}_{2}$ incubator at $37^{\circ} \mathrm{C}$. Cell proliferation assays were done in the same medium.

\section{Cell proliferation assays}

Cells (NIH-3T3, HeLa) were plated $\left(5.10^{3}\right.$ cells/well) in 96well microtiter plates. After incubation at $37^{\circ} \mathrm{C}$ for $6 \mathrm{~h}, \mathrm{XCL}$ was added to the wells (35-140 $\left.\mu \mathrm{g} \cdot \mathrm{ml}^{-1}\right)$, and incubation proceeded for 1-3 days. Controls cells were incubated in the absence of lectin. SF9 cells were plated $\left(15.10^{3}\right.$ cells/well) in 96-well microtiter plates containing SF900 medium and incubated for 1-3 days at room temperature using the same range of XCL concentrations.

Proliferation of the three cell lines was assessed using the WST-1 reagent. The reagent was directly added to the well at $10 \%(\mathrm{v}: \mathrm{v})$ in triplicates. A range of cell density was included at each assay to plot the standard curve. A spectrophotometer was used to read the absorbance at $450 \mathrm{~nm}$ as recommended by the manufacturer.

Proliferation rates were estimated as the ratio of the number of cells after 2 days/number of cells at the beginning of the experiment. Effect of the lectin was estimated as the ratio of the proliferation rate observed in the presence of lectin/the proliferation rate observed for the reference.

\section{Cell adhesion assays}

To investigate the relationship between the abundance of adhesion proteins at the cell surface and the role of the fungal lectin, HeLa cells were treated with trypsin/EDTA $0.05 \%$ / $0.02 \%(\mathrm{w} / \mathrm{v}$ ) in PBS for different durations (from 5-15 min) before lectin incubation in the medium. Indeed, trypsin is known to digest the proteins on the cell surface involved in adhesion. The longer the cells were exposed to trypsin the less the effective adhesion proteins were available. After the trypsin treatment, the suspended cells (5000 cells) were incubated with $70 \mu \mathrm{g} \cdot \mathrm{ml}^{-1}$ of XCL, and the number of adherent cells after 1-6 h was assessed using the WST-1 test. Growth medium was removed and the adherent cells were washed with PBS (10 mM phosphate buffer pH 7.2, $150 \mathrm{mM}$ $\mathrm{NaCl}$ ) before adding fresh DMEM medium and the WST-1 reagent at $10 \%(\mathrm{v}: \mathrm{v})$ in triplicates. Materials and conditions to perform the colorimetric assays were as described above.

\section{Flow cytometry analyses}

HeLa or NIH-3T3 cells were plated in 6-cm plates, and then incubated for 2 or 3 days in the presence of XCL at 35 or $70 \mu \mathrm{g} . \mathrm{ml}^{-1}$. The cells were collected by centrifugation, washed in PBS, fixed in ice-cold $70 \%$ ethanol for $30 \mathrm{~min}$ and again washed in PBS. Cells were suspended in PBS, and an equal volume of DNA extraction buffer ( $4 \mathrm{mM}$ citric acid in $0.2 \mathrm{M} \mathrm{Na}_{2} \mathrm{HPO}_{4}$ ) was added and incubation proceeded for $5 \mathrm{~min}$. Cells were then centrifuged and incubated $30 \mathrm{~min}$ in PBS containing $20 \mu \mathrm{g} . \mathrm{ml}^{-1}$ propidium iodide, $0.2 \mathrm{mg} \cdot \mathrm{ml}^{-1}$ RNAse A, $0.1 \%$ Triton X-100. Fluorescence of propidiumiodide-stained cells was measured with a FACSCalibur cytometer and analysed with Cell Quest software (BectonDickinson). For each experiment, 10,000 events were counted. 


\section{Immunofluorescence microscopy}

\section{Cell surface binding of XCL}

Cells (HeLa or NIH-3T3) from the stock cultures were suspended by 5 min trypsin treatment and incubated with 70 $\mu \mathrm{g} . \mathrm{ml}^{-1} \mathrm{XCL}$ under gentle agitation in DMEM/10\% fetal bovine serum, at room temperature. Control cells were incubated in the absence of lectin. After 15 min of incubation, the cells were washed with PBS, fixed in PBS/3.6\% formaldehyde for $30 \mathrm{~min}$ at room temperature and washed in PBS. Non-specific sites were saturated in PBS/3\% BSA (w/v) for $1 \mathrm{~h}$ at room temperature and the cells were then incubated for $1 \mathrm{~h}$ at room temperature with the rabbit polyclonal antibody directed against XCL after dilution to $1 / 400$ in PBS/1\% BSA. After two washes in PBS, the cells were incubated with the FITC labelled anti-rabbit antibody (dilution 1/400) for $1 \mathrm{~h}$ at room temperature. The cells were washed twice in PBS before being incubated for $5 \mathrm{~min}$ at room temperature with a $0.2 \mu \mathrm{g} / \mathrm{ml}$ solution of DAPI in PBS and washed again in PBS. After each step of washing and incubation, cells were centrifuged at $1000 \mathrm{~g}$ for $5 \mathrm{~min}$ at room temperature. The supernatant was discarded and the cells used in the next step. Finally, the cells were covered in Moviol (Calbiochem) and mounted on glass slides.

\section{Actin cytoskeleton labelling}

Cells were plated on coverslips, and treated by XCL at 70 $\mu \mathrm{g} . \mathrm{ml}^{-1}$ for $16 \mathrm{~h}$. They were fixed in $3.6 \%$ formaldhehyde/ PBS for $90 \mathrm{~min}$ and permeabilized in $0.5 \%$ Triton X-100/PBS for $5 \mathrm{~min}$. The coverslips were blocked with PBS/3\% BSA $(\mathrm{w} / \mathrm{v})$ for $1 \mathrm{~h}$, and then incubated with mouse anti-actin monoclonal antibody for $1 \mathrm{~h}$. The cells were then washed with PBS and stained for $45 \mathrm{~min}$ with FITC-secondary antibody. They were DAPI stained and samples were mounted in Sigma mounting medium and examined by fluorescence microscopy.

\section{Results}

\section{Effect of XCL on cell proliferation}

XCL showed effects on the proliferation of both adherent cells lines: HeLa and NIH-3T3. A diminution of their proliferation rate, proportional to the XCL concentration, was observed after 2 days of incubation (Fig. 1A). On the contrary, no significant effect on the growth of the non-adherent cell line SF9 was observed during the 3 days of incubation with XCL (Fig. 1A). Cell mortality was observed by trypan blue dye labelling for HeLa and NIH-3T3 cell lines at the second and third day of incubation with the lectin (data not shown). This cytotoxicity was proportional to the XCL concentration, as shown in Fig. 1B for Hela cells incubated for 2 days with different doses of the lectin.
A

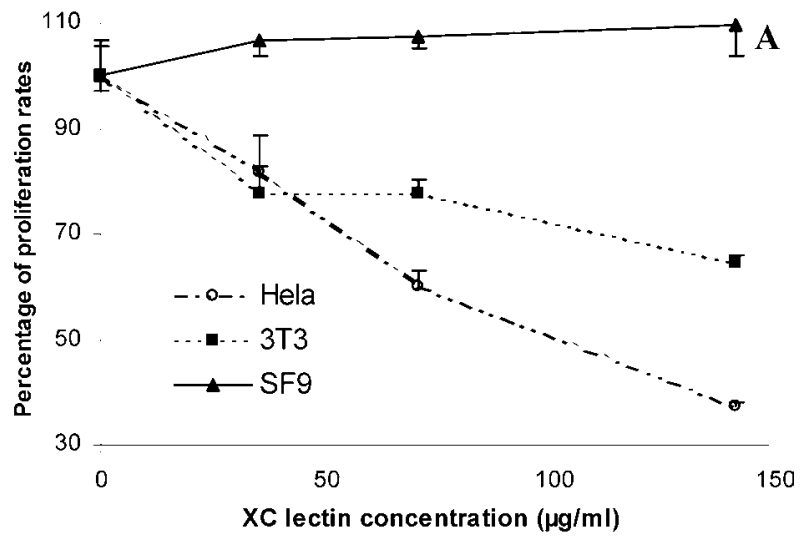

B

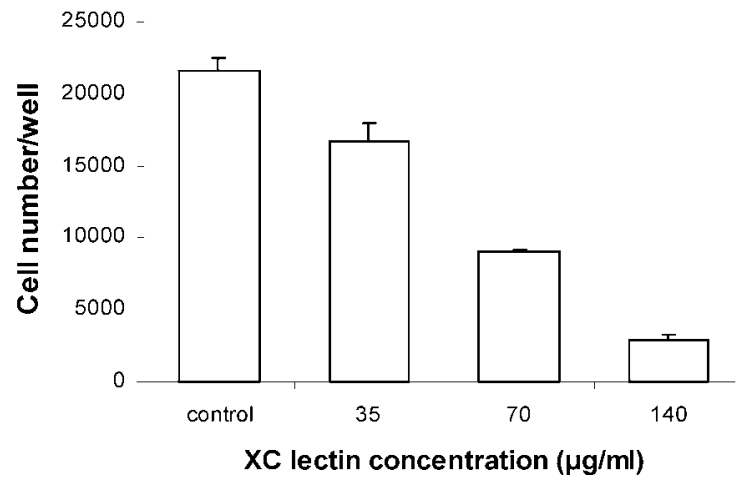

Fig. 1. Effect of XCL lectin on cell proliferation. (A) Dose response relationship for the effect of XCL on the proliferation rate of Hela, NIH-3T3 and SF9 cells after a 2-day culture. A $0-140 \mu \mathrm{g} \cdot \mathrm{ml}^{-1}$ concentration range of fungal lectin was used in the incubation medium. Control cells were incubated in absence of XCL, their values of proliferation rates were $2.37 \pm$ $0.13,1.45 \pm 0.05,2.34 \pm 0.14$ for Hela, NIH-3T3 and SF9 respectively. (B) Effect of different doses of XCL on the growth of Hela cells after 2 days of incubation. Five thousand cells were plated at day 0 .

\section{Cell cycle distribution}

To determine the nature of the antiproliferative effect of XCL, we investigated whether the lectin could interfere with the cell cycle or induce an apoptotic process. HeLa and NIH-3T3 (data not shown) cells were exposed to different doses of XCL for 2 or 3 days, then subjected to flow cytometric analysis. In all cases, the XCL-treated cells exhibited a DNA pattern similar to that of the non-treated cells (Fig. 2). Furthermore, and in agreement with nucleus morphological observation (data not shown), no subG1 DNA peak, characteristic of a reduction in DNA content, was observed in any case. Thus, XCL did not disrupt the cell cycle nor did it induce apoptosis. 


\section{Effect of XCL on the adhesion of trypsin-treated cells}

Since XCL only showed an antiproliferative effect on the adherent cells lines, we considered that the lectin might inhibit adhesion processes essential for the growth of these cells. To assess the relationship between XCL and adhesion protein at the cell surface, we determined the adherent HeLa cell number after different durations of trypsin treatment followed or not by incubation with XCL (Fig. 3). Whatever the trypsin exposure duration and with or without incubation with $\mathrm{XCL}$, the number of adherent cells reached a plateau within

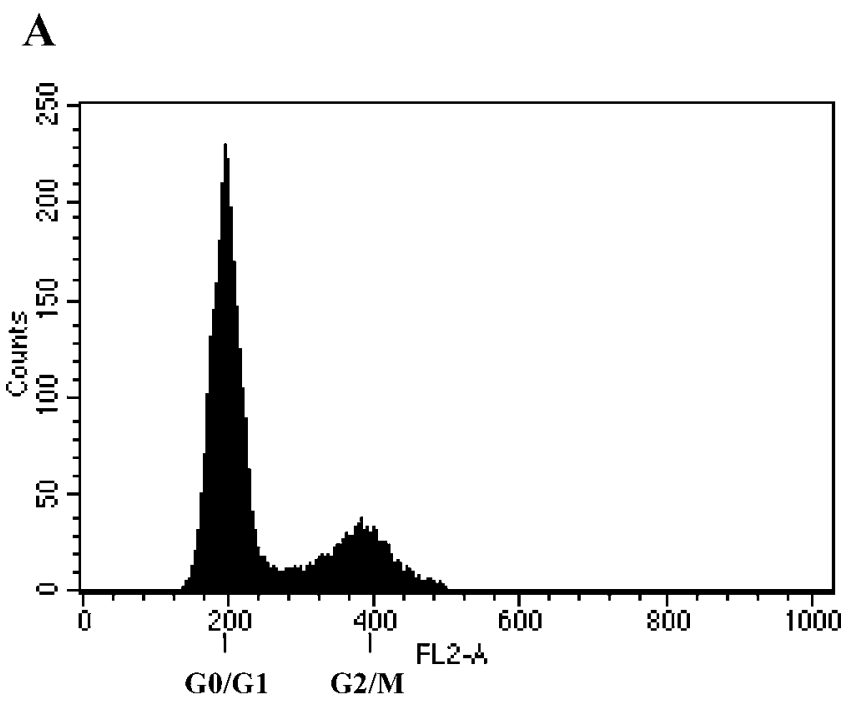

B

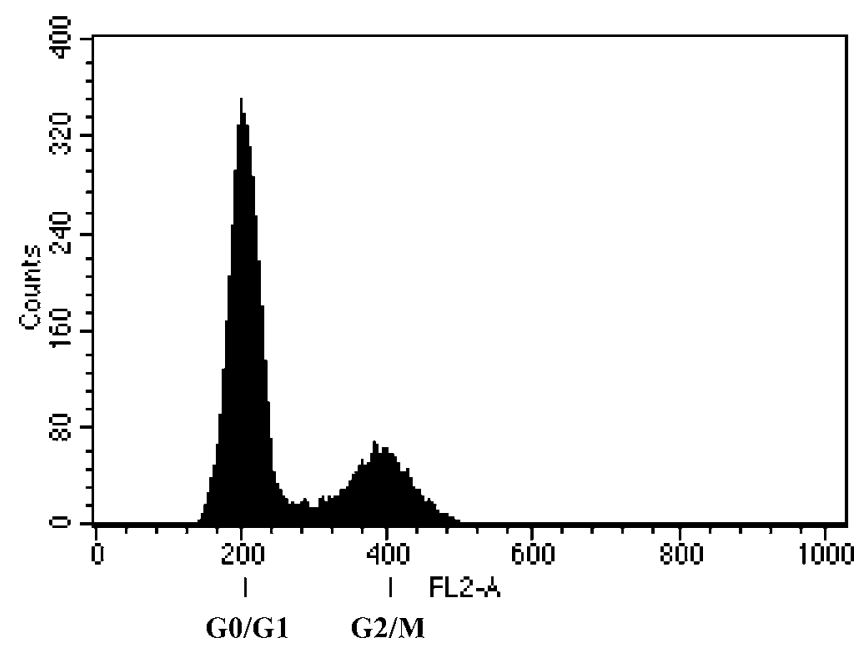

Fig. 2. Cell cycle analysis on Hela cells incubated for 3 days in presence of XCL $\left(70 \mu \mathrm{g} \cdot \mathrm{ml}^{-1}\right)$. DNA patterns were similar in control cells (A) and $\mathrm{XCL}$ treated (B) cells.
$2 \mathrm{~h}$, indicating that the major adhesion processes were completed during that period. As expected, the longer the cells were exposed to trypsin the lower the number of adherent cells, reflecting the diminution of effective adhesion proteins at the cell surface. A reduction of the adherent cell number $(\sim 50 \%)$ was observed when the trypsin treatment was extended from 5-10 min (compare Fig. 3A, control/Fig. 3B, control). When the trypsin treatment was prolonged to 15 min, a $\sim 70 \%$ reduction of cell adhesion was observed (compare Fig. 3A, control/Fig. 3C, control).

In the presence of XCL, a marked inhibition of cell adhesion was observed. Whatever the duration of trypsin exposure about $60 \%$ of the cells failed to adhere and remained floating in the medium.

These experiments suggest that XCL interacts at the cell surface with extramembrane glycoproteins, inhibiting cellmatrix interactions.

\section{Cell surface binding of XCL}

Next, we carried out immunofluorescence experiments to visualise the binding of XCL at the cell surface which could explain the anti-adhesion effect of XCL. Hela cells were incubated under gentle agitation with the fungal lectin for 15 min, then immunolabelled with anti-XCL antibodies, and DAPI stained to visualise the cell nuclei (Figs 4C and 4D). Whereas no staining was found on lectin untreated cells (Fig. 4A), specific punctuate labelling of the cell surface was present on the XCL treated cells (Fig. 4B). These observations confirm the rapid binding of large amounts of XCL to cell surface receptors.

\section{$X C L$ induces actin cytoskeleton modifications}

Morphological changes were observed by microscopic examination of Hela cells cultured in the presence of XCL (data not shown). Whereas control cells were well spread on the plastic, XCL treated cells were more refractile, rounded in shape and failed to spread correctly although they were still attached to the plastic plate. Since the actin cytoskeleton plays a key role in cell morphogenesis and cell adhesion, we investigated the possibility that the modifications of cell-substratum adhesion caused by XCL is correlated with a rearrangement of the actin cytoskeleton. Immunofluorescence studies showed that in control cells, actin is mostly organized in circumferential microfilament bundles (Fig. 5A), whereas XCL treated cells display a distinctive organization of actin microfilaments in the cell cortex, characterized by radial actin microspikes (Fig. 5B). Thus, XCL induced the formation of distinct structures involved in cell-substratum adhesion. 
A

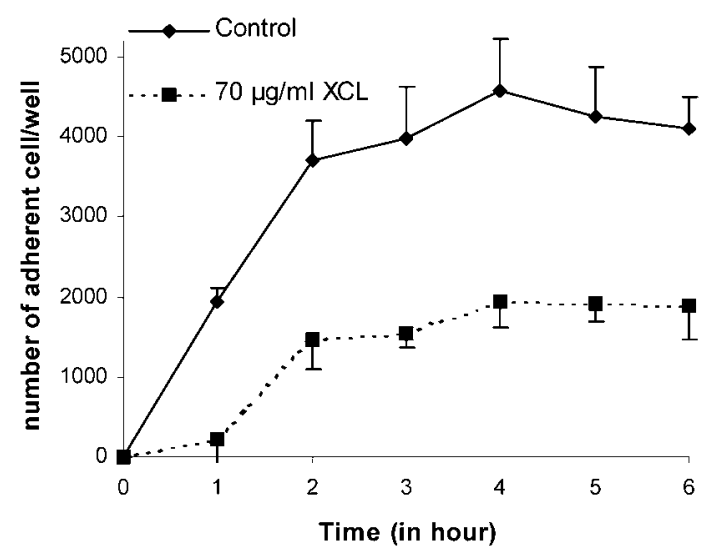

B

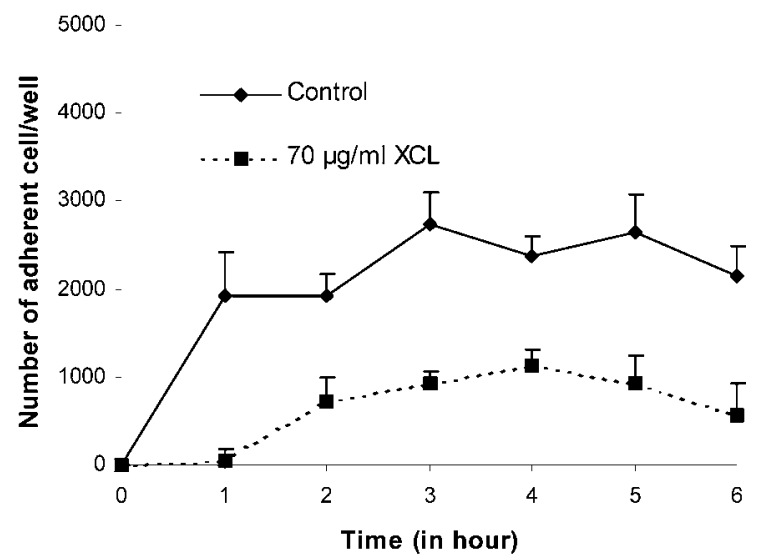

C

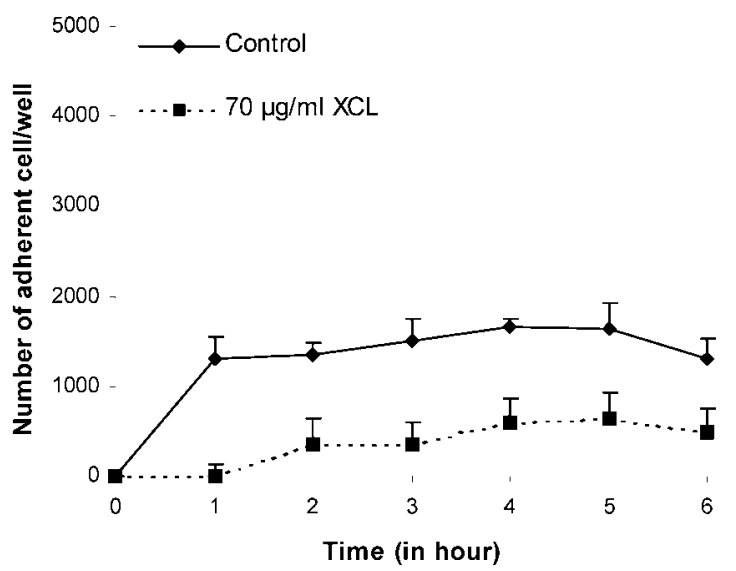

Fig. 3. Effect of trypsin treatment duration coupled with XCL incubation of Hela cells. Cells submitted to a 5 (A), 10 (B) and 15 min (C) of trypsin exposure were incubated with $70 \mu \mathrm{g} . \mathrm{ml}^{-1}$ of XCL final concentration. Controls used for comparison correspond to lectin untreated cells.

\section{Discussion}

In the first part of this work, lectin from $X$. chrysenteron was shown to inhibit the proliferation of two mammalian cell lines, namely Hela and NIH-3T3. The inhibitory effects of lectins on cell adhesion are a widespread phenomenon observed in a number of cell lines and involve protein sugar interactions. For example, galectin-8 inhibited the growth of three cell lines including Hela [7]. Didemnum ternatanum lectin (DTL) also inhibits the proliferative activity of Hela cells grown on solid substrate and acts to slow cell growth, interfering in cell attachment and spreading [1]. Whereas both adherent cell lines studied here were sensitive to the fungal lectin, no effect on the SF9 growth was observed whatever the lectin concentration in the medium. As the insect cell line was able to proliferate in suspension and had no need to adhere to an extracellular matrix, we hypothesized that XCL interfere with the cells adhesion process.

The cell mortality of Hela and NIH-3T3 cells occurring from the second to the third day of incubation with XCL was not due to an apoptotic process. Indeed, FACS analysis combined with nuclei observations of XCL treated cells using DAPI staining allowed us to conclude that the fungal lectin did not induce apoptosis. We also determined that XCL did not have any effect on the cell cycle. This result suggests that cell death originates from a disruption of cell adherence and supports the hypothesis that in the same manner, the antiproliferative effect of XCL originates from inhibition of cellmatrix interactions.

Cell-matrix interactions occur through a variety of cell adhesion receptors [8]. Exogenously added adhesion molecules such as integrins, cadherins but also lectins control some biological processes through interaction with cell complementary glycoconjugates [8]. To study the interactions between XCL and the adhesion protein at cell surface, Hela cells were treated with trypsin for different durations. The longer was the trypsin treatment, the smaller the number of adherent cell. When Hela cells were incubated with XCL, the adherent cell density decreased further. The adherence reduction can be explained by the reduction of available adhesion protein due to the action of trypsin and to cell coating by the fungal lectin which rapidly blocked the last adhesion protein present on cell surface. From 1-2 h, cells which were able to adhere were spread. Whereas most of cell lines are commonly spread after $2 \mathrm{~h}$ at $37^{\circ} \mathrm{C}$ [7], the early phases of cell adhesion occurred in the first $30 \mathrm{~min}$. At this time, early focal contacts are present at the edges of the cells. Within $1 \mathrm{~h}$ of adhesion, cells are maximally enlarged while at $3 \mathrm{~h}$ the adhesive process is completed [9]. In accordance with their proposed functions, lectins enhance or inhibit cell matrix interactions. Although little is known about the exact role of lectins in regulating cell adhesion, current models suggest that binding of lectins to matrix proteins elicits an inhibitory effect due to a steric hindrance of cell-matrix interactions $[10,11]$. The latter depend to a large extent upon the engagement of specific extra-cellular matrix proteins with cell surface integrins [12-14]. Integrins mediate cell adhesion, migration and in- 


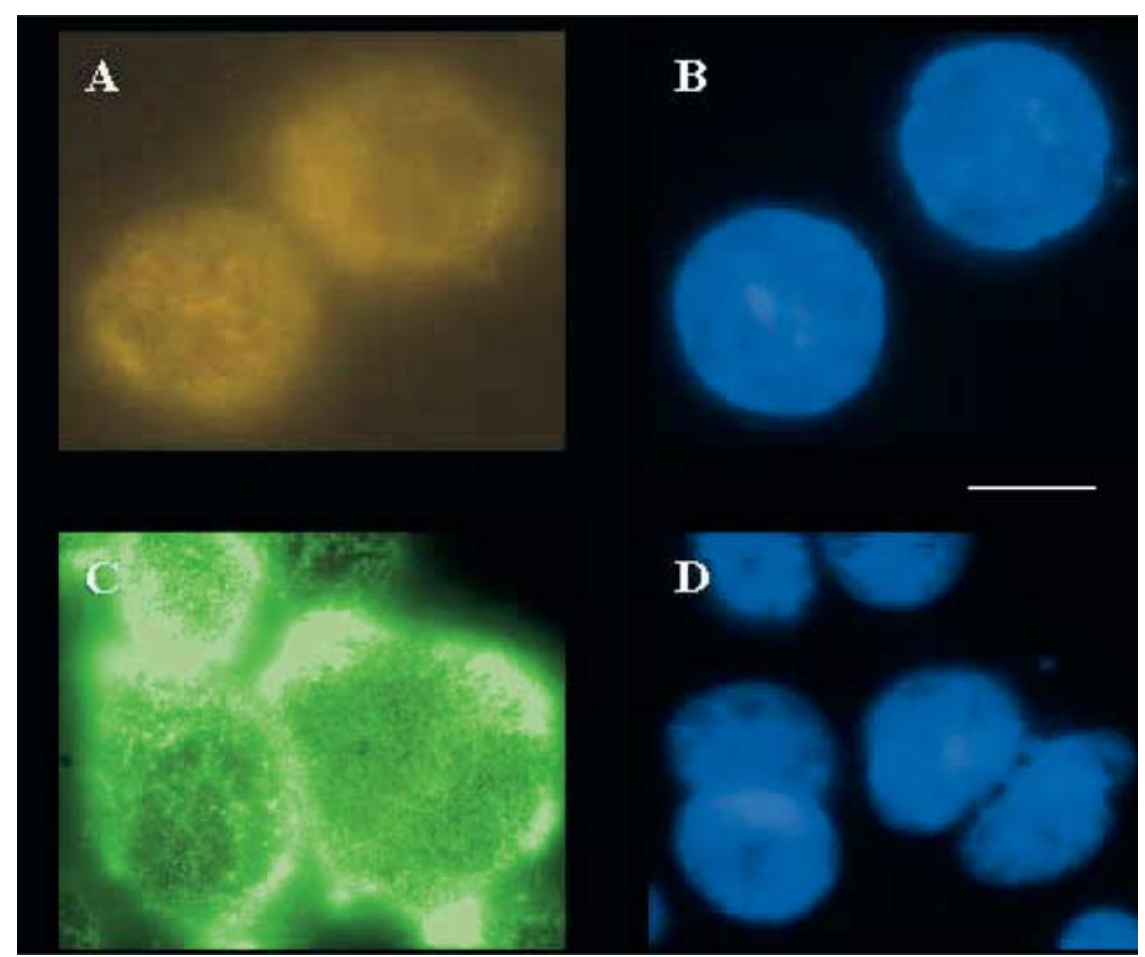

Fig. 4. Cell surface binding of XCL lectin after a $15 \mathrm{~min}$ incubation at room temperature. Hela control untreated cells and treated with $70 \mu \mathrm{\mu g} . \mathrm{ml}^{-1}$ of XCL were fixed and stained with DAPI (B and D respectively) to visualize the nucleus (blue) and were labelled with polyclonal rabbit anti-XCL antibodies (A and $\mathrm{C}$ respectively) that recognize native XCL form (green). Bar: $10 \mu \mathrm{m}$.

vasion and have been implicated in the regulation of many cellular functions [14]. When present as a soluble ligand, the lectin forms a complex with cell surface proteins that negatively regulates cell adhesion. Thus, our results suggest that, like several galectins $[15,16], \mathrm{XCL}$ is a modulator of cell adhesion.

Immunofluorescence revealed that cells became completely covered by the fungal lectin within $15 \mathrm{~min}$. Other lectins have already been shown to rapidly cover cell and tissue surfaces. Epithelial cells from several insect guts were found to be covered by Galanthus nivalis (GNA) and Con-A lectins added to the insect diet [17, 18]. The accumulation and persistence of lectins on cell and tissue may additionally act by disrupting the multiple metabolic processes carried out by this cell or this tissue [18].

The effect of XCL on cell-matrix adhesion was confirmed by the induction of dramatic changes in the organization of the actin cytoskeleton of Hela cells. Various actin-containing structures involved in cell-substratum interactions have been described, including focal adhesion, point contacts, filipodia, and podosomes [19, 20]. The balance of adhesive receptors ligated at the cell surface for cell-matrix attachment serves to regulate the type of substratum adhesion contact assembled and subsequent cytoskeletal organization. We hypothesize that the interaction of XCL with adhesive receptors
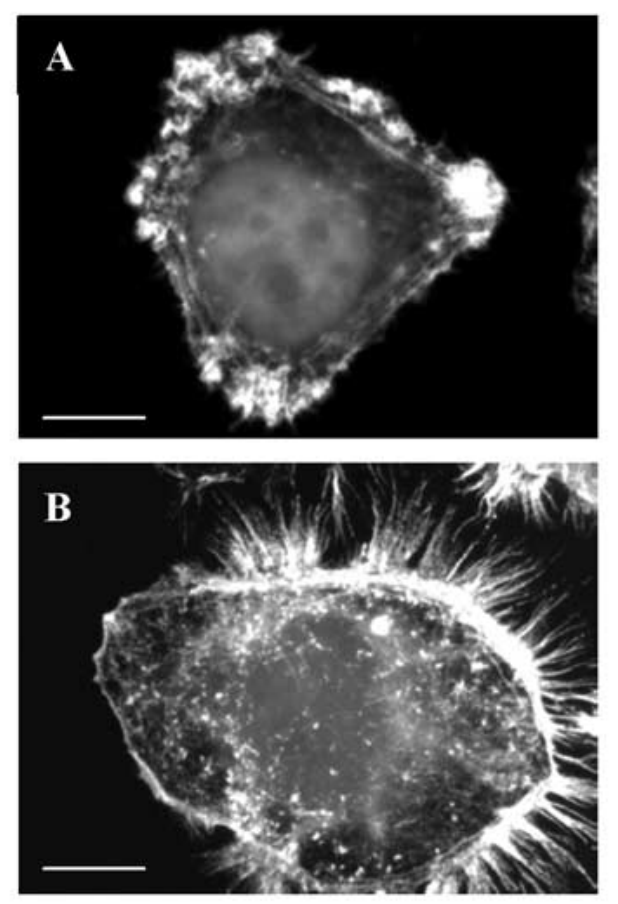

Fig. 5. Effect of XCL on the actin cytoskeleton of Hela cells. Control untreated cells (A) and treated (B) during $16 \mathrm{~h}$ with $70 \mu \mathrm{g} \cdot \mathrm{ml}^{-1}$ of XCL were fixed and labelled with polyclonal rabbit anti-Actin antibodies (white). Bar: $10 \mu \mathrm{m}$. 
triggers signalling events leading to the reorganization of the actin cytoskeleton. Thus, in response to the XCL coating, the cell would display a distinctive organization of actin microfilaments characterized by radial actin microspikes.

The adhesion of cells to the surrounding extracellular matrix is a necessary process to allow cells to survive, proliferate, and differentiate. Defects in these pathways associated with several external signals, such as those from adhesion proteins, provide the basis for cell function abnormalities [21]. The present work suggests that soluble XCL binds receptors on the cell surface that mediate cell-matrix interactions. The modification of cell-matrix attachment induced by the XCL coating was coupled to a clear inhibitory effect on cell proliferation.

\section{Acknowledgements}

This work was supported by Syngenta. Frédéric Francis was granted by a fellowship from the Organisation for Economic Co-operation and Development (OECD) under the program of Biological Resource Management for Sustainable Agricultural Systems.

\section{References}

1. Odintsova NA, Belogortseva NI, Khomenko AV, Chikalovets IV, Luk'yanov PA: Effect of lectin from the ascidian on the growth and the adhesion of Hela cells. Mol Cell Biochem 221: 133-138, 2001

2. Peumans WJ, Van Damme JM: Lectins as plant defense proteins. Plant Physiol 109: 347-352, 1995

3. Badache A, Lehmann S, Kuchler-Bopp S, Hand N, Zanetta JP: An endogenous lectin and its glycoprotein ligands are triggering basal and axon-induced Schwann cell proliferation. Glycobiology 5: 371-383, 1995

4. Yu L, Fernig DG, Smith JA, Milton JD, Rhodes JM: Reversible inhibition of proliferation of epithelial cell lines by Agaricus bisporus (edible mushroom) lectin. Cancer Res 53: 4627-4632, 1993

5. Rosén S, Ek B, Rask L, Tunlid A: Purification and characterization of a surface lectin from the nematode-trapping fungus Arthrobotrys oligospora. J Gen Microbiol 138: 2663-2672, 1992
6. Trigueros V, Lougarre A, Ali-Ahmed D, Rabhe Y, Guillot J, Chavant L, Fournier D, Paquereau L: Xerocomus chrysenteron lectin: Identification of a new pesticidal protein. Biochim Biophys Acta 1621: 292298, 2003

7. Levy Y, Arbel-Goren R, Hadari YR, Eshhar S, Ronen D, Elhanany E, Geiger B, Zick Y: Galectin-8 functions as matricellular modulator of cell adhesion. J Biol Chem 276: 31285-31295, 2001

8. Boudreau N, Bissel MJ: Extracellular matrix signaling: Integration of form and function in normal and malignant cells. Curr Opin Cell Biol 10: 640-646, 1998

9. Defillipi P, Olivo C, Venturino M, Dolce L, Silengo L, Tarone G: Actin cytoskeleton organization in response to integrin-mediated adhesion. Microscopy Res Tech 47: 67-78, 1999

10. Cooper DN, Massa SM, Barondes SH: Endogenous muscle lectin inhibits myoblast adhesion to laminin. J Cell Biol 115: 1437-1448, 1991

11. Sato S, Hughes RC: Binding specificity of a baby hamster kidney lectin for $\mathrm{H}$ type I and II chains, plolylactosamine glycans, and appropriately glycosylated forms of laminin and fibronectin. J Biol Chem 267: 6983-6990, 1992

12. Clark EA, Brugge JS: Integrins and signal transduction pathways, the road taken. Science 268: 233-239, 1995

13. Hynes RO: Cell adhesion: Old and new questions. Trends Cell Biol 9: 33-37, 1999

14. Schwartz MA, Schaller MD, Ginsberg MH: Integrins: Emerging paradigms of signal transduction. Annu Rev Cell Div Biol 11: 549-599, 1995

15. Hadari YR, Arbel-Goren R, Levy Y, Amsterdam A, Alon R, Zakut R, Zick Y: Galectin-8 binding to integrins inhibits cell adhesion and induces apoptosis. J Cell Sci 113: 2385-2397, 2000

16. Barondes SH, Cooper DNW, Gitt MA, Leffler H: Galectins. Structure and function of a large family of animal lectins. J Biol Chem 269: 20807-20810, 1994

17. Fitches E, Woodhouse SD, Edwards JP, Gatehouse JA: In vitro and in vivo binding of snowdrop (Galanthus nivalis agglutinin, GNA) and jackbean (Canavalia ensiformis, Con A) lectins within tomato moth (Lacanobia oleracea) larvae; mechanisms of insecticidal action. J Insect Physiol 47: 777-787, 2001

18. Pusztai A, Ewen SWB, Grant G, Peumans WJ, Van Damme EJ, Rubio EJ, Bardocz S: Relationship between survival and binding of plant lectins during small intestinal passage and their effectiveness as growth factors. Digestion 46: 308-316, 1990

19. Geiger B, Bershadsky A, Pankov R, Yamada KM: Transmembrane crosstalk between the extracellular matrix-cytoskeleton crosstalk. Nat Rev Mol Cell Biol 2: 793-805, 2001

20. Adams JC: Characterization of cell-matrix adhesion requirements for the formation of fascin microspikes. Mol Biol Cell 8: 2345-2363, 1997

21. Turner CE: Paxillin and focal adhesion signalling. Nat Cell Biol 2: 231232,2000 
